\title{
Clinical and electrophysiological effects of intravenous quinidine in man $^{1}$
}

\author{
DAVID S. HIRSCHFELD, CLARENCE T. UEDA, MALCOLM ROWLAND, \\ AND MELVIN M. SCHEINMAN ${ }^{2}$ \\ From the Medical Service, San Francisco General Hospital, and the Department of Medicine and the \\ Cardiovascular Research Institute, University of California, San Francisco, U.S.A.
}

Quinidine gluconate (total dose 4.4 to $9.1 \mathrm{mg} / \mathrm{kg}$ ) was infused intravenously over 22 minutes in 20 patients with either frequent premature ventricular contractions or supraventricular arrhythmias, 16 of whom had bundle-branch block. Therapeutic plasma quinidine levels (3 to $7 \mathrm{mg} / \mathrm{l}$ ) were achieved in 15 . Heart rate, atrioventricular nodal, and infranodal conduction times did not change significantly. The QRS duration increased significantly from $128 \pm 30$ to $134 \pm 29$ ms at peak plasma quinidine levels $(P<0 \cdot 01)$. Mild hypotension occurred during infusion in most patients. Two patients had a severe but transient toxic response characterised by hypotension, nausea, vomiting, and diaphoresis. Atrioventricular dissociation with escape His bundle or fascicular rhythm occurred in 1 patient with sinus bradycardia. Bundle-branch block does not contraindicate administration of quinidine. Quinidine gluconate administered intravenously $(0.3$ to 0.4 $\mathrm{mg} / \mathrm{kg}$ per min) is frequently associated with hypotension and should be used only in an intensive care setting and with careful monitoring of blood pressure.

Oral administration of quinidine has proved to be effective and safe for the control of atrial and ventricular arrhythmias provided that plasma levels are kept within the therapeutic range (Sokolow and Ball, 1956), whereas the intravenous use of quinidine has been associated with serious untoward reactions (Armbrust and Levine, 1950; Chapman, 1945; Hepburn and Rykert, 1937; Riseman and Linenthal, 1941; Strong and Munroe, 1940) and is generally considered to be contraindicated (Selzer, 1972). Quinidine delays conduction and increases refractoriness of the His-Purkinje system and slows conduction in ventricular muscle. Because of these actions, quinidine is believed by some to be relatively contraindicated in patients with bundlebranch block (Sokolow and Perloff, 1961). In the study reported here, we attempted to correlate the electrophysiological effects of quinidine on atrioventricular and intraventricular conduction with plasma drug levels in patients with bundle-branch block in an effort to define a rate of intravenous administration of this drug in man which yields

'Supported in part by funds from the Bay Area Heart Research Committee and in part by research grants HL 06285 and GM 16496 from the National Institutes of Health, Bethesda, Maryland.

'This study was performed during tenure of the American Heart Association Teaching Scholar in Cardiology.

Received for publication 23 April 1976 therapeutic blood levels within a relatively short period of time but without undue toxic effects.

\section{Subjects and methods}

Twenty patients with either frequent premature ventricular contractions or supraventricular arrhythmias in whom prolonged therapy with oral quinidine was anticipated were studied. Informed consent was obtained and the study conducted in accordance with a protocol approved by the Committee on Human Experimentation of the University of California, San Francisco. No patient was receiving other antiarrhythmic agents at the time of the study. A hexapolar electrode catheter was introduced percutaneously via the right femoral vein, and His bundle recordings were obtained by previously described techniques (Damato et al., 1969; Scheinman et al., 1973). External scalar leads X, Y, and inverse $Z$ of the Frank orthogonal system were recorded simultaneously with the His bundle electrogram at a paper speed of $100 \mathrm{~mm} / \mathrm{s}$. The atrioventricular nodal conduction time (AH interval) was measured from the earliest rapid deflection of the atrial electrogram to the initial deflection of the His bundle depolarisation. The conduction time from bundle to ventricle (HQ interval) 
was measured from the initial His deflection to the earliest onset of ventricular depolarisation recorded on the external leads; the onset of the $\mathrm{V}$ deflection in the His bundle recordings was not used.

Preliminary studies showed that infusion of less than $3 \mathrm{mg} / \mathrm{kg}$ body weight over 22 minutes failed to produce therapeutic blood levels of quinidine ( 3 to $7 \mathrm{mg} / \mathrm{l}$ ). In the present study, quinidine gluconate was diluted in $50 \mathrm{ml} 5$ per cent dextrose in water and administered over 22 minutes by a Harvard constant infusion pump to provide a total dose of from 4.4 to $9.1 \mathrm{mg} / \mathrm{kg}$ quinidine gluconate (average 6.9) at infusion rates of 0.20 to $0.45 \mathrm{mg} / \mathrm{kg}$ per min (average 0.34). Blood specimens for quinidine assay were withdrawn every 5 minutes during infusion and for $\mathbf{2 0}$ minutes afterwards from a polyethylene catheter inserted into a vein in the opposite arm. Simultaneously with withdrawal of blood specimens, the systemic blood pressure was measured by the cuff method, the His bundle electrogram recorded, and 30 second electrocardiographic recordings were obtained in order to count premature beats. Patients were observed closely and asked to report any symptoms during the study.

Plasma quinidine levels were measured by two techniques: (1) a standard colorimetric method involving alkaline extraction into ethylene chloride (Brodie et al., 1946), and (2) a more specific extraction procedure coupled to a thin layer chromatography separation (Ueda et al., 1976). Plasma quididine levels are expressed as $\mathrm{mg} / \mathrm{l}$ of quinidine base. Where applicable, the data were analysed using Student's paired $t$ test.

\section{Results}

Pertinent clinical information, peak plasma quinidine levels, and electrophysiological data for each patient are summarised in Tables 1 and 2. Twelve patients manifested either left bundle-branch block, right bundle-branch block with left anterior fascicular block, or right bundle-branch block with left posterior fascicular block; of these, 8 had prolonged HQ intervals ( $>55 \mathrm{~ms}$ ). Four patients had right bundle-branch block alone or isolated left anterior fascicular block; of these, one had a prolonged $\mathrm{HQ}$ interval. Four had no intraventricular conduction abnormality; of these, one had a slightly prolonged HQ interval $(58 \mathrm{~ms})$. Of the 20 patients, 13 had premature beats at the time of the study.

Plasma quinidine levels tended to increase progressively during infusion, and in all but one patient the peak quinidine level was achieved at the end of the infusion (Fig. 1). Therapeutic plasma quinidine levels were achieved ( 3 to $7 \mathrm{mg} / \mathrm{ml}$ ) when the infusion was stopped in 15 patients. There was no significant difference in plasma quinidine levels determined by the colorimetric assay and the more specific chromatographic technique. Values referred

Table 1 Pertinent clinical and electrocardiographic data and amount of quinidine administered

\begin{tabular}{|c|c|c|c|c|c|c|}
\hline Case No. & Cardiac disease & $C H F$ & Conduction disturbance & Arrhythmia & $\begin{array}{l}\text { Amount quinidine infused } \\
(\mathrm{mg} / \mathrm{kg})\end{array}$ & $\begin{array}{l}\text { Peak quinidine plasma level } \\
(m g / l)\end{array}$ \\
\hline $\begin{array}{l}1 \\
2 \\
3 \\
4 \\
5 \\
6 \\
7 \\
8 \\
9 \\
10 \\
11 \\
12 \\
13 \\
14 \\
15 \\
16 \\
17 \\
18 \\
19 \\
20 \\
\text { Mean } \pm \text { SD }\end{array}$ & $\begin{array}{l}\text { CAD } \\
\text { CAD } \\
\text { CAD } \\
\text { CAD } \\
\text { CAD } \\
\text { CAD } \\
\text { Cardiomyopathy } \\
\text { RHD } \\
\text { Unknown } \\
\text { Unknown } \\
\text { Cardiomyopathy } \\
\text { Unknown } \\
\text { CAD } \\
\text { HHD } \\
\text { CAD } \\
\text { CAD } \\
\text { HHD } \\
\text { Unknown } \\
\text { Cardiomyopathy } \\
\text { Unknown }\end{array}$ & $\begin{array}{l}\text { Yes } \\
\text { Yes } \\
\text { Yes } \\
\text { Yes } \\
\text { Yes } \\
\text { No } \\
\text { Yes } \\
\text { Yes } \\
\text { No } \\
\text { No } \\
\text { Yes } \\
\text { No } \\
\text { No } \\
\text { Yes } \\
\text { No } \\
\text { Yes } \\
\text { Yes } \\
\text { Yes } \\
\text { No } \\
\text { Yes }\end{array}$ & $\begin{array}{l}\text { LAHB } \\
\text { LAHB, RBBB } \\
\text { LBBB } \\
\text { LAHB } \\
\text { RBBB } \\
\text { None } \\
\text { LPHB, RBBB } \\
\text { LBBB, SB } \\
\text { None } \\
\text { LAHB, RBBB } \\
\text { LAHB, SB } \\
\text { LBBB } \\
\text { None } \\
\text { None } \\
\text { LPHB, RBBB } \\
\text { LBBB } \\
\text { LBBB } \\
\text { LAHB, RBBB } \\
\text { LAHB, RBBB } \\
\text { LBBB }\end{array}$ & $\begin{array}{l}\text { PVC } \\
\text { PVC } \\
\text { PAC } \\
\text { PVC } \\
\text { PVC } \\
\text { PVC } \\
\text { PVC } \\
\text { PAT* } \\
\text { PVC } \\
\text { PAC } \\
\text { PJC } \\
\text { PAC } \\
\text { PAT` } \\
\text { Atrial flutter } \\
\text { PVC } \\
\text { PVC } \\
\text { PVC } \\
\text { PVC } \\
\text { PVC, PAC } \\
\text { PVC, PAC }\end{array}$ & $\begin{array}{l}7 \cdot 5 \\
7 \cdot 1 \\
7 \cdot 2 \\
9 \cdot 1 \\
5 \cdot 4 \\
9 \cdot 0 \\
6 \cdot 7 \\
7 \cdot 3 \\
4 \cdot 6 \\
5 \cdot 8 \\
6 \cdot 6 \\
7 \cdot 4 \\
9 \cdot 0 \\
8 \cdot 8 \\
9 \cdot 0 \\
5 \cdot 4 \\
7 \cdot 2 \\
5 \cdot 2 \\
6 \cdot 0 \\
4 \cdot 4 \\
6 \cdot 9 \pm 1 \cdot 5\end{array}$ & $\begin{array}{l}3 \cdot 1 \\
4 \cdot 9 \\
3 \cdot 5 \\
4 \cdot 3 \\
3 \cdot 3 \\
8 \cdot 4 \\
0 \cdot 8 \\
5 \cdot 8 \\
1 \cdot 4 \\
4 \cdot 6 \\
4 \cdot 1 \\
3 \cdot 0 \\
4 \cdot 0 \\
5 \cdot 8 \\
2 \cdot 9 \\
5 \cdot 3 \\
2 \cdot 8 \\
3 \cdot 7 \\
1 \cdot 6 \\
3 \cdot 2 \\
3 \cdot 8 \pm 1 \cdot 7\end{array}$ \\
\hline
\end{tabular}

CHF, congestive heart failure; CAD, coronary artery disease; RHD, rheumatic heart disease; HHD, hypertensive heart disease; LAHB, left anterior hemiblock; RBBB, right bundle-branch block; LBBB, left bundle-branch block; LPHB, left posterior hemiblock; SB, sinus bradycardia; PAC, premature atrial contractions; PVC, premature ventricular contractions; PAT, paroxysmal atrial tachycardia; PJC, premature junctional contractions.

*Not at time of study. 
Table 2 Blood pressure and electrophysiological intervals before administration of quinidine and at peak plasma quinidine level

\begin{tabular}{|c|c|c|c|c|c|c|c|c|c|c|}
\hline \multirow[t]{3}{*}{ Case No. } & & & \multicolumn{8}{|c|}{ Intervals (ms) } \\
\hline & \multicolumn{2}{|c|}{ Blood pressure ( $\mathrm{mmHg}$ ) } & \multicolumn{2}{|l|}{$R R$} & \multicolumn{2}{|l|}{$A H$} & \multicolumn{2}{|l|}{$H Q$} & \multicolumn{2}{|l|}{$Q R S$} \\
\hline & Before & Peak & Before & Peak & Before & Peak & Before & Peak & Before & Peak \\
\hline $\begin{array}{l}1 \\
2 \\
3 \\
4 \\
5 \\
6 \\
7 \\
8 \\
9 \\
10 \\
11 \\
12 \\
13 \\
14 \\
15 \\
16 \\
17 \\
18 \\
19 \\
20 \\
\text { Mean } \pm S D\end{array}$ & $\begin{array}{l}130 / 80 \\
180 / 80 \\
170 / 70 \\
120 / 80 \\
135 / 90 \\
110 / 70 \\
120 / 70 \\
110 / 60 \\
120 / 85 \\
170 / 105 \\
110 / 70 \\
114 / 72 \\
110 / 85 \\
200 / 90 \\
140 / 85 \\
125 / 60 \\
130 / 80 \\
130 / 70 \\
140 / 90 \\
100 / 70 \\
132 \pm 27 / 78 \pm 11 \\
\end{array}$ & $\begin{array}{c}110 / 76 \\
160 / 70 \\
160 / 60 \\
90 / 55 \\
115 / 70 \\
90 / 60 \\
80 / 50 \\
105 / 60 \\
80 / 60 \\
110 / 60 \\
80 / 50 \\
102 / 64 \\
90 / 70 \\
165 / 90 \\
130 / 80 \\
125 / 60 \\
105 / 70 \\
140 / 80 \\
120 / 80 \\
58 / 0 \\
113 \pm 26 / 67 \pm 11 \\
0.01\end{array}$ & $\begin{array}{r}780 \\
885 \\
730 \\
810 \\
580 \\
600 \\
820 \\
1070 \\
880 \\
850 \\
1015 \\
720 \\
740 \\
380 \\
750 \\
610 \\
760 \\
665 \\
600 \\
835 \\
754 \pm 158 \\
\end{array}$ & $\begin{array}{r}750 \\
1000 \\
750 \\
700 \\
600 \\
640 \\
870 \\
1120 \\
720 \\
780 \\
1100 \\
670 \\
650 \\
460 \\
600 \\
650 \\
665 \\
600 \\
640 \\
835 \\
740 \pm 171 \\
\text { JS }\end{array}$ & $\begin{array}{c}105 \\
105 \\
100 \\
120 \\
90 \\
90 \\
75 \\
75 \\
80 \\
80 \\
190 \\
80 \\
60 \\
90 \\
110 \\
125 \\
110^{\star} \\
95 \\
90 \\
99 \pm 26\end{array}$ & $\begin{array}{c}105 \\
105 \\
90 \\
115 \\
85 \\
85 \\
80 \\
80 \\
50 \\
80 \\
180 \\
75 \\
60 \\
- \\
85 \\
115 \\
115 \\
110^{\star} \\
100 \\
100 \\
95 \pm 27 \\
\text { NS }\end{array}$ & $\begin{array}{l}40 \\
45 \\
65 \\
45 \\
95 \\
58 \\
80 \\
80 \\
45 \\
60 \\
50 \\
55 \\
45 \\
55 \\
50 \\
70 \\
70 \\
-85 \\
85 \\
66 \pm 29\end{array}$ & $\begin{array}{c}45 \\
50 \\
65 \\
45 \\
100 \\
65 \\
70 \\
60 \\
50 \\
60 \\
50 \\
65 \\
50 \\
50 \\
50 \\
70 \\
70 \\
- \\
85 \\
80 \\
65 \pm 27 \\
\text { NS }\end{array}$ & $\begin{array}{l}105 \\
135 \\
140 \\
100 \\
110 \\
105 \\
170 \\
155 \\
80 \\
125 \\
100 \\
145 \\
70 \\
80 \\
130 \\
140 \\
170 \\
130 \\
150 \\
140 \\
128 \pm 30 \\
\quad P<\end{array}$ & $\begin{array}{l}125 \\
145 \\
140 \\
100 \\
110 \\
135 \\
180 \\
170 \\
80 \\
135 \\
120 \\
160 \\
80 \\
80 \\
140 \\
150 \\
170 \\
130 \\
160 \\
140 \\
134 \pm 29 \\
0.01\end{array}$ \\
\hline
\end{tabular}

*A-to right bundle potential; His not obtained.

to henceforth are those determined by the chromatographic method.

\section{EFFECTS ON SINUS RATE,}

ATRIOVENTRICULAR, AND

INTRAVENTRICULAR CONDUCTION

There was no significant change in heart rate during or after quinidine infusion. Mean heart rate was $78 \pm 16$ beats/min before quinidine and $79 \pm 18$

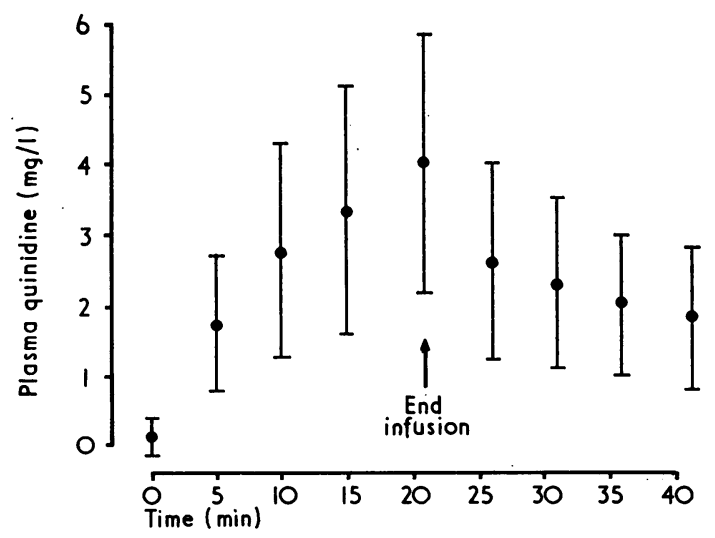

Fig. 1 Mean $( \pm S D)$ plasma quinidine level during and after infusion of quinidine gluconate. $\uparrow$ indicates time of termination of the infusion. beats/min at the time of peak plasma quinidine level. There was no significant difference between mean atrioventricular nodal conduction time before quinidine $(99 \pm 26 \mathrm{~ms})$ and a peak plasma quinidine level $(95 \pm 27 \mathrm{~ms})$. Two patients with prolonged control atrioventricular nodal conduction time (120 and $190 \mathrm{~ms}$ ) showed slight decrease in AH time at peak plasma quinidine levels (to 115 and $180 \mathrm{~ms}$, respectively).

The HQ interval was prolonged ( $>55 \mathrm{~ms}$ ) in 10 of the 19 patients in whom it could be measured; the right bundle potential rather than the His potential was recorded in one patient. There was no significant difference between mean $\mathrm{HQ}$ before quinidine $(66 \pm 29 \mathrm{~ms})$ and at peak plasma quinidine level $(65 \pm 27 \mathrm{~ms})$. At peak plasma quinidine level, HQ was shorter in 4, longer in 7 , and unchanged in 8 patients. In addition, there was no significant difference in absolute or per cent change in mean HQ before quinidine or at peak plasma quinidine level in the sub-group of 10 patients with prolonged control HQ compared with those with normal control HQ intervals. A His bundle electrocardiogram in a representative patient before quinidine infusion and at the time of peak plasma quinidine level is shown in Fig. 2. In one patient whose control tracing showed sinus bradycardia, left bundle-branch block, a split His potential, and a prolonged $\mathrm{HQ}$ interval, the sinus rate slowed even further and 


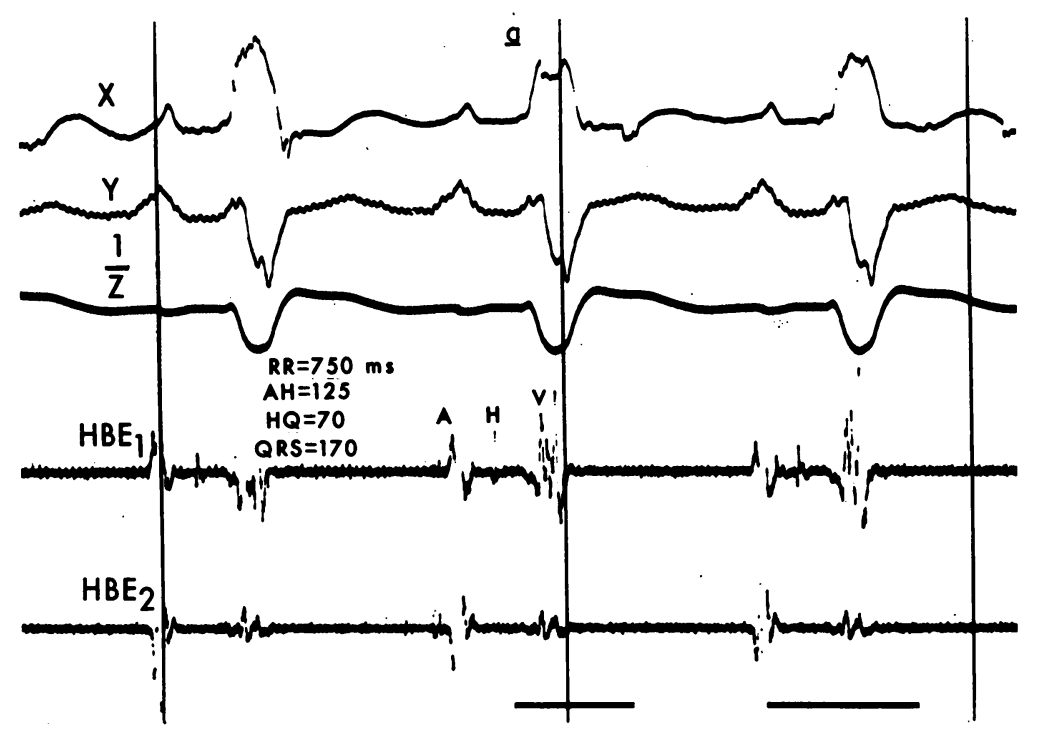

Fig. 2 His bundle electrograms (HBE) of Case 17. (a) Before infusion of quinidine gluconate. $A=$ atrial potential, $H=H i$ is spike, $V=$ ventricular potential. (b) $H B E$ at peak plasma quinidine level. $A H$ is $10 \mathrm{~ms}$ shorter than in (a) and $H Q$ and $Q R S$ are unchanged.

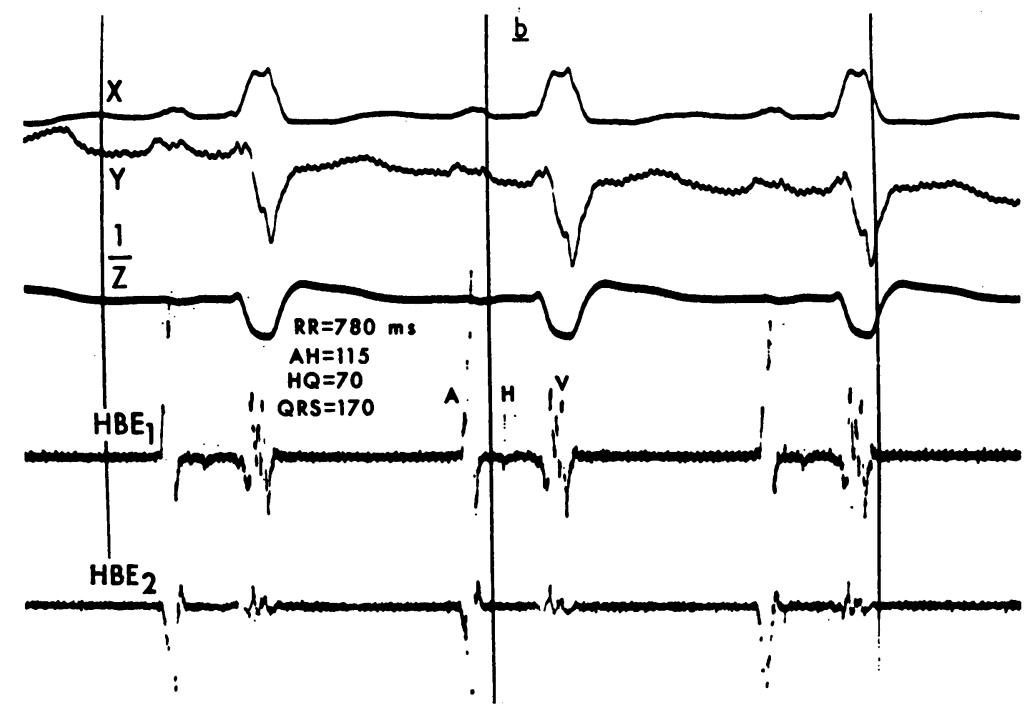

atrioventricular dissociation developed (Fig. 3), with the block localised within the His bundle during drug infusion. Second degree or complete atrioventricular block did not develop in any other patient.

Mean QRS duration increased significantly from $128 \pm 30$ before quinidine to $134 \pm 29 \mathrm{~ms}$ at peak plasma quinidine level $(P<0.01)$, but there was no significant difference in the absolute or per cent change in 7 patients with either normal or left anterior fascicular block compared with the 13 patients with bundle-branch block. In no patient did the QRS duration increase by greater than 28 per cent.

\section{EFFECTS OF CONGESTIVE HEART FAILURE}

Of the 20 patients, 13 were in congestive heart failure with varying degrees of compensation at the time of the study. The group in heart failure showed no significant difference from those not in heart failure, in heart rate or atrioventricular or intraventricular conduction times either before or after quinidine infusion. Furthermore, there was no difference in the peak plasma level of quinidine 


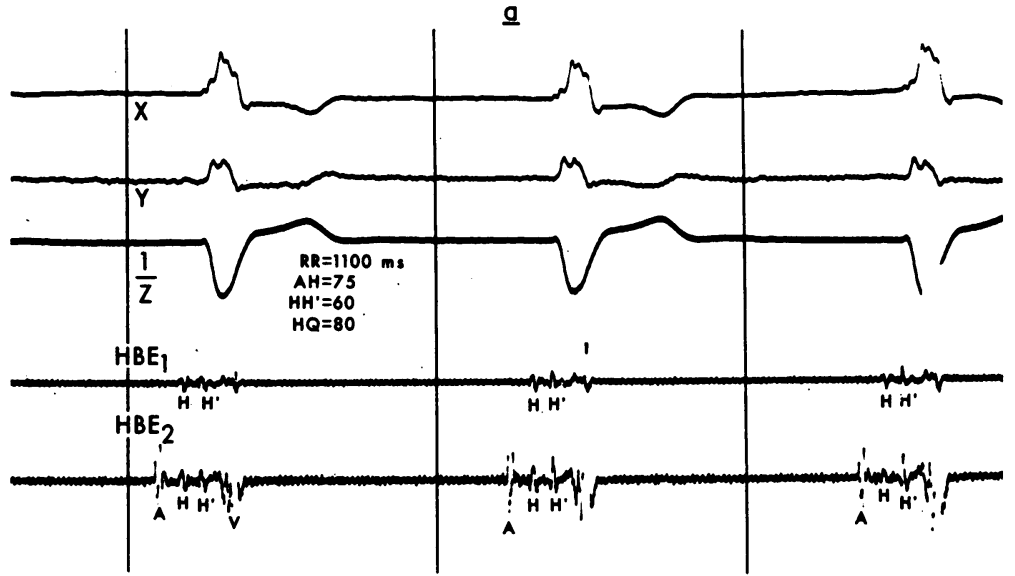

b

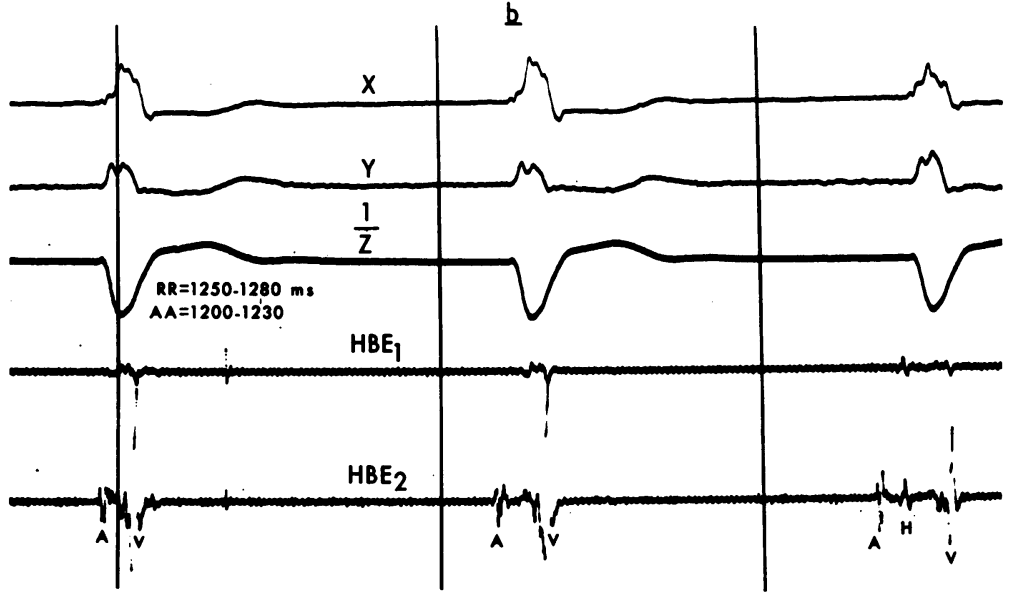

c

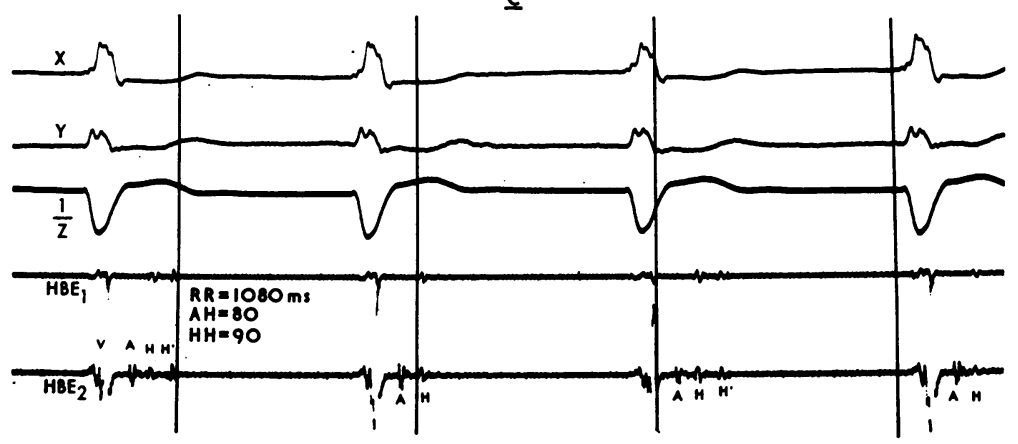

Fig. 3 His bundle electrograms of Case 18. (a) Control tracing showing two spikes $\left(H H^{\prime}\right)$ falling between $A$ and $V$ representing split His potential with spontaneous atrial cycle length of $1100 \mathrm{~ms}$. (b) 5 minutes after termination of infusion, atrioventricular dissociation is present. (The atrial cycle length is 1230; the ventricular cycle length is 1280 ms.) Because of proximity of the atrial and ventricular electrogram, $\mathrm{His}$ spikes are not seen in the first two complexes. (c) Atrioventricular dissociation within the His-Purkinje system. Note that $H H^{\prime}$ has lengthened. $H^{\prime}$ is missing in alternate beats, which is probably because of block within the His. The ventricular pacemaker is probably in the distal His bundle, but a focus in the right fascicle cannot be excluded. 
achieved, when normalised for height and weight, in the patients in heart failure compared with the patients not in heart failure.

\section{ARRHYTHMIA CONTROL}

Five patients were having premature supraventricular beats and 8 were experiencing premature ventricular beats during the study. One of the subjects had both premature atrial contractions and premature ventricular contractions. Ectopic beats were decreased in frequency ( $<75 \%$ of control) at the time of peak plasma quinidine level in all 9 patients in whom therapeutic levels were achieved. The effect on frequency of premature ventricular contractions in a representative patient is shown in Fig. 4.

\section{TOXIC SIDE-EFFECTS}

The mean of the systemic blood pressures dropped significantly $(P<0.01)$ from control values $(132 \pm$ $27 / 78 \pm 11 \mathrm{mmHg}$ ) by 5 minutes after starting infusion and was lowest $(113 \pm 26 / 67 \pm 11 \mathrm{mmHg})$ at the end of infusion when plasma quinidine levels were highest. Five patients had a drop in systolic blood pressure to $<100 \mathrm{mmHg}$ but remained asymptomatic. In 2 other patients, diaphoresis and nausea occurred concomitantly with a distinct fall in blood pressure and small changes in heart rate; both responded favourably to raising the legs and stopping the infusion. Their plasma quinidine levels were not excessive $(1.4$ and $3.2 \mathrm{mg} / \mathrm{l})$ at the time of hypotension and the rates of infusion ( 0.35 and $0.20 \mathrm{mg} / \mathrm{kg}$ per min) were no more rapid than in the remaining 18 patients (mean $0.34 \mathrm{mg} / \mathrm{kg}$ per $\mathrm{min})$. No other toxic responses to quinidine infusion were observed, and no patients experienced tinnitus, vertigo, or diarrhoea.

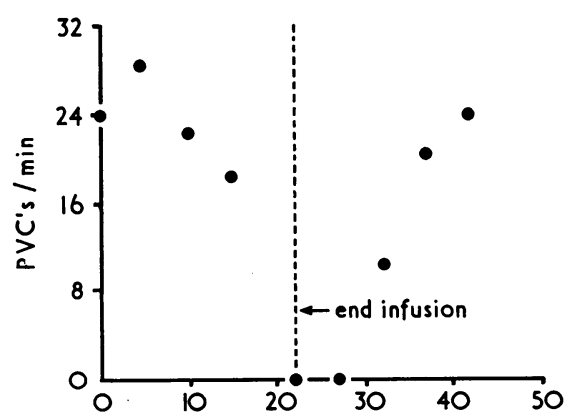

Fig. 4 Frequency of premature ventricular contractions during quinidine infusion in Case 6 illustrating suppression of ectopic beats at termination of infusion and return of premature ventricular contractions afterwards.

\section{Discussion}

\section{EFFECT OF QUINIDINE}

Quinidine is considered by many to be the mainstay of chronic oral antiarrhythmic therapy. It is of obvious practical importance for the clinician to be aware of the relative risks of quinidine therapy for patients with atrioventricular or intraventricular conduction delay. Experimental studies in animals showed that administration of quinidine in amounts that produce blood levels considered to be within the therapeutic range in man result in little change in atrioventricular nodal conduction time (Wallace et al., 1966) but definite increases in infranodal and intraventricular conduction times (Wallace et al., 1966; Sokolow, 1951; Vaughan Williams, 1958; Swain and Weidner, 1957). For this reason, some believe that the presence of bundle-branch block constitutes a relative contraindication to the use of quinidine (Sokolow and Perloff, 1961). The electrocardiograms in 16 of our patients had either unifascicular or bifascicular block and 10 had prolonged infranodal conduction times. Therapeutic blood levels of quinidine resulted in no significant change in atrioventricular conduction times and in small increases in intraventricular conduction times. Though the QRS duration increased significantly $(P<0.01)$ after quinidine, the QRS axis did not change nor did a new bundle-branch block develop in any patient. In one patient with sinus bradycardia and a prolonged sinus node recovery time, sinus slowing, and atrioventricular dissociation associated with an escape His bundle or fascicular focus developed during quinidine infusion. The degree of atrioventricular block did not increase in any other patient.

The only other study in which His bundle recordings were used to assess the effects of quinidine gluconate in man is that of Josephson et al. (1974), in which the drug was administered intramuscularly. Their results are similar to ours with regard to the effect of quinidine on heart rate and atrioventricular nodal and intraventricular conduction times but differ in that a small but significant increase in infranodal conduction time (mean $6 \mathrm{~ms}$ ) was observed in their study. The reason for the difference is uncertain, though in the study of Josephson et al. (1974), larger doses (600 to $800 \mathrm{mg}$ quinidine gluconate) were administered and His bundle recordings were made at higher plasma quinidine levels $(4.6$ versus $3.8 \mathrm{mg} / \mathrm{l})$. It is also possible that the hypotension caused by intravenous administration of the drug in our patients provoked catecholamine stimulation or increased sympathetic tone which tended to diminish the direct effect of quinidine on the infranodal conduction system. 
Reports on the safety of intravenous administration of quinidine have yielded conflicting conclusions. Severe toxic reactions (Chapman, 1945; Hepburn and Rykert, 1937; Riseman and Linenthal, 1941; Strong and Munroe, 1940) and death (Armbrust and Levine, 1950; Acierno and Gubner, 1951) were attributed to the intravenous route and some clinicians have expressed the view that the intravenous route is never (Selzer, 1972) or almost never (Goldberg, 1974; Friedberg, 1966) acceptable medical practice. In these reports either large doses of quinidine were administered (intravenously) rapidly or the patients appeared to be moribund at the time of infusion. However, Clagett (1950) administered quinidine lactate intravenously in doses up to $3.25 \mathrm{~g}$ but at infusion rates comparable to ours, and the only side-effects observed were nausea and vomiting in 3 of the 13 patients studied. In his study, as in ours, quinidine administration was associated with a decrease or abolition of supraventricular or ventricular arrhythmias and did not produce bundle-branch or atrioventricular block or increased ventricular ectopia. Asymptomatic mild to modera:e decreases in systemic blood pressure occurred in 17 of our patients, including reduction of systolic pressure to $<100 \mathrm{mmHg}$ in 5 , and a toxic reaction characterised by the abrupt onset of nausea, intense diaphoresis, and severe hypotension occurred in 2 patients during infusion. Both of these patients actually received smaller amounts of quinidine because infusion was terminated prematurely, and plasma quinidine levels were in the subtherapeutic or low therapeutic range $(1.4$ and $3.2 \mathrm{mg} / \mathrm{l})$. In all patients who had a fall in blood pressure, the hypotension persisted for 5 to 10 minutes after termination of infusion. Our data suggest that careful monitoring of the systemic blood pressure is mandatory when quinidine is administered intravenously. Moreover, an alphasympathetic agonist should be readily available because the hypotensive effect of intravenous quinidine is most likely the result of reversible alphareceptor blockade (Ferrer et al., 1948; Luchi et al., 1963) rather than of a direct myocardial action.

\section{PLASMA QUINIDINE LEVELS}

Although there was a progressive rise in plasma quinidine level in each patient during infusion of quinidine, the levels ranged widely even after correction for rates of infusion and body weight. This finding is probably related to the rate and extent of drug distribution because only trivial amounts of the drug would be expected to be metabolised or excreted over the relatively short period of the study. Regardless of differences in rate and extent of drug distribution, we found that doses of 7 to
$9 \mathrm{mg} / \mathrm{kg}$ quinidine gluconate regularly resulted in peak plasma quinidine levels within the therapeutic range. Of further interest was the observation that mean peak plasma quinidine levels did not differ significantly between patients with (10) or without (10) heart failure. These findings are similar to those described by Bellet et al. (1971), who found no significant difference in mean plasma quinidine levels between normal subjects and patients with congestive heart failure 2 hours after an oral dose of $600 \mathrm{mg}$ quinidine; however, the levels were significantly higher in patients with heart failure than in normal subjects 4,6 , and 24 hours after the oral dose. These findings are consistent with our own unpublished observations that the higher plasma quinidine levels found in patients with heart failure are related to decreased drug clearance rather than to diminished volume of distribution.

\section{CLINICAL IMPLICATIONS}

In this study, the haemodynamic and electrophysiological effects of intravenous administration of quinidine gluconate which resulted in a relatively rapid achievement of therapeutic plasma quinidine levels were assessed. All the patients but one who received 7 to $9 \mathrm{mg} / \mathrm{kg}$ achieved therapeutic plasma quinidine levels within 22 minutes. In a recent study by Wellens and Durrer (1974) $4 \mathrm{mg} / \mathrm{kg}$ of quinidine was infused intravenously at a rate of $0.8 \mathrm{mg} / \mathrm{kg}$ per $\mathrm{min}$ in patients with the Wolff-Parkinson-White syndrome and 5 of the 6 patients became hypotensive, with sweating, restlessness, and tachycardia. In our study, the average total dose was about twice as great, but the slower rates of infusion (mean rate of $0.34 \mathrm{mg} / \mathrm{kg}$ ) probably accounted for the lower incidence of toxicity. Nevertheless, the slower rates of infusion used in the present study were still associated with an unacceptably high incidence of hypotensive reactions. This study has also shown that therapeutic levels of quinidine were effective in decreasing or abolishing cardiac arrhythmias and were safe for patients with atrioventricular or intraventricular conduction abnormalities in that no higher degrees of atrioventricular block or increased ventricular ectopic activity were encountered. One patient with sinus bradycardia, however, developed transient atrioventricular dissociation owing to further slowing of the sinus rate. For patients requiring parenteral quinidine therapy, intravenous administration appears to have several advantages over the intramuscular route: there is a more rapid and uniform achievement of therapeutic plasma levels; drug administration may be readily terminated should untoward effects occur; and the intravenous route is painless.

Nevertheless, the relatively high incidence of 
hypotensive reactions encountered suggests that intravenous quinidine administration should be reserved for critical situations where first line drugs are ineffective and only used with ready availability of an alpha-sympathetic agonist. Though untoward effects disappeared shortly after termination of the infusion and no long-term sequelae were observed, this regimen should rarely, if ever, be used in critically ill patients with hypoxia and/or electrolyte abnormalities (Watanabe et al., 1963; Watanabe and Dreifus, 1967; Holland, 1957), in patients with sinus bradycardia, or in patients receiving drugs that may potentiate quinidine effects.

\section{Addendum}

Since completion of this manuscript, 7 additional patients received $8 \mathrm{mg} / \mathrm{kg}$ of quinidine intravenously and no untoward effects were observed.

The authors wish to thank Gunnard Modin for statistical analyses.

\section{References}

Acierno, L. J., and Gubner, R. (1951). Utility and limitations of intravenous quinidine in arrhythmias. American Heart fournal, 41, 733-741.

Armbrust, C. A., Jr., and Levine, S. A. (1950). Paroxysmal ventricular tachycardia: study of 107 cases. Circulation, $1,28-40$.

Bellet, S., Roman, L. R., and Boza, A. (1971). Relation between serum quinidine levels and renal function. Studies in normal subjects and patients with congestive failure and renal insufficiency. American fournal of Cardiology, 27, 368-371.

Brodie, B. B., Udenfriend, S., and Baer, J. E. (1946). Analysis of basic organic compounds in biological tissues: I. Isolation prior to estimation. Federation Proceedings, 5, 124-125.

Chapman, D. W. (1945). Observations on 2 patients with paroxysmal ventricular tachycardia treated by intravenous administration of quinidine lactate. American Heart fournal, 30, 276-283.

Clagett, A. H., Jr. (1950). Intravenous use of quinidine, with particular reference to ventricular tachycardia. American fournal of the Medical Sciences, 220, 381-387.

Damato, A. N., Lau, S. H., Helfant, R. H., Stein, E., Berkowitz, W. D., and Cohen, S. I. (1969). Study of atrioventricular conduction in man using electrode catheter recordings of His bundle activity. Circulation, 39, 287-296.

Ferrer, M. I., Harvey, R. M., Werkö, L., Dresdale, D. T., Cournand, A., and Richards, D. W., Jr. (1948). Some effects of quinidine sulfate on the heart and circulation in man. American Heart fournal, 36, 816-837.

Friedberg, C. K. (1966). Diseases of the Heart, 3rd ed., p. 553. W. B. Saunders, Philadelphia.

Goldberg, L. I. (1974). Pharmacology of cardiovascular drugs. In The Heart, Arteries and Veins, 3rd ed., p. 1704. Ed. by J. W. Hurst, R. B. Logue, R. C. Schlant, and N. K. Wenger. McGraw-Hill, New York.
Hepburn, J., and Rykert, H. E. (1937). Use of quinidine sulfate intravenously in ventricular tachycardia. American Heart fournal, 14, 620-623.

Holland, W. C. (1957). A possible mechanism of action of quinidine. American fournal of Physiology, 190, 492-494.

Josephson, M. E., Seides, S. F., Batsford, W. P., Weisfogel, G. M., Akhtar, M., Caracta, A. R., Lau, S. H., and Damato, A. N. (1974). The electrophysiological effects of intramuscular quinidine on the atrioventricular conducting system in man. American Heart fournal, 87, 55-64.

Luchi, R. J., Helwig, J., Jr., and Conn, H. L., Jr. (1963). Quinidine toxicity and its treatment. An experimental study. American Heart fournal, 65, 340-348.

Riseman, J. E. F., and Linenthal, H. (1941). Paroxysmal ventricular tachycardia; its favorable prognosis in absence of acute cardiac damage and its treatment with parenterally administered quinidine dihydrochloride. American Heart fournal, 22, 219-229.

Scheinman, M. M., Weiss, A., and Kunkel, F. (1973). His bundle recordings in patients with bundle branch block and transient neurologic symptoms. Circulation, 48, 322-330.

Selzer, A. (1972). The use and abuse of quinidine. Heart Lung, 1, 755.

Sokolow, M. (1951). The present status of therapy of the cardiac arrhythmias with quinidine. American Heart Fournal, 42, 771-797.

Sokolow, M., and Ball, R. E. (1956). Factors influencing conversion of chronic atrial fibrillation with special reference to serum quinidine concentration. Circulation, 14, 568-583.

Sokolow, M., and Perloff, D. B. (1961). The clinical pharmacology and use of quinidine in heart disease. Progress in Cardiovascular Diseases, 3, 316-330.

Strong, G. F., and Munroe, D. S. (1940). Paroxysmal ventricular tachycardia, with report of unusual case. American Heart fournal, 19, 486-491.

Swain, H. H., and Weidner, C. L. (1957). A study of substances which alter intraventricular conduction in the isolated dog heart. Fournal of Pharmacology and Experimental Therapeutics, 120, 137-146.

Ueda, C. T., Ballard, B. E., and Rowland, M. (1976). Concentration-time effects in quinidine disposition kinetics in Rhesus monkeys. Fournal of Pharmacokinetics and Biopharmaceutics. In the press.

Vaughan Williams, E. M. (1958). The mode of action of quinidine on isolated rabbit atria interpreted from intracellular potential records. British fournal of Pharmacology and Chemotherapy, 13, 276-287.

Wallace, A. G., Cline, R. E., Sealy, W. C., Young, W. G., Jr., and Troyer, W. G., Jr. (1966). Electrophysiologic effects of quinidine. Studies using chronically implanted electrodes in awake dogs with and without cardiac denervation. Circulation Research, 19, 960-969.

Watanabe, Y., and Dreifus, L. S. (1967). Interactions of quinidine and potassium on atrioventricular transmission. Circulation Research, 20, 434-446.

Watanabe, Y., Dreifus, L. S., and Likoff, W. (1963). Electrophysiologic antagonism and synergism of potassium and antiarrhythmic agents. American fournal of Cardiology, 12, 702-710.

Wellens, H. G., and Durrer, D. (1974). Effect of procaine amide, quinidine, and ajmaline in the Wolff-ParkinsonWhite syndrome. Circulation, 50, 114-120.

Requests for reprints to Editorial Office, Room 4101, San Francisco General Hospital, 1001 Potrero Avenue, San Francisco, California 94110, U.S.A. 